\title{
An Overview of Dyslexia: Definition, Characteristics, Assessment, Identification, and Intervention
}

\author{
Jane Roitsch*, Silvana Watson \\ Department of Communication Disorders and Special Education, Old Dominion University, Norfolk, USA
}

Email address:

jroitsch@odu.edu (J. Roitsch), swatson@odu.edu (S. Watson)

${ }^{*}$ Corresponding author

\section{To cite this article:}

Jane Roitsch, Silvana Watson. An Overview of Dyslexia: Definition, Characteristics, Assessment, Identification, and Intervention. Education Journal. Vol. 7, No. 4, 2019, pp. 81-86. doi: 10.11648/j.sjedu.20190704.11

Received: July 19, 2019; Accepted: August 15, 2019; Published: September 3, 2019

\begin{abstract}
Background: Dyslexia is a developmental brain-based type of learning disability that affects a person's ability to read and spell words. Best estimates place 5 percent to 10 percent of the population with the condition, but the incidence of dyslexia is challenging to pinpoint, as the definition of dyslexia varies throughout research. Objective: The purpose of this article is to provide an overview of dyslexia, its characteristics, assessment and identification, and intervention techniques for the condition. Results: Although the disorder varies from person to person, common characteristics among people with dyslexia include difficulty with phonological skills, low accuracy and fluency of reading, poor spelling, and/or rapid visual-verbal responding. Dyslexia is a neurological condition and can be inherited, and recent studies have identified a number of genes that may predispose an individual to developing dyslexia. Identification of dyslexia early requires recognition of characteristics such as difficulty associating sounds with letters, reading dysfluencies, spelling difficulties, challenges with written expression and poor handwriting. Dyslexia assessments can guide professions in ways to best administer treatment, such as via strategies to enhance word training and improve decoding skills. All of these interventions have shown to benefit the reading and writing abilities of persons with dyslexia. Conclusions: The unique nature and presentation of dyslexia varies among individuals. The importance of understanding as much as possible and keeping abreast of the assessment and intervention strategies available is critical to minimizing the long-term effects of dyslexia.
\end{abstract}

Keywords: Identification and Causes of Dyslexia, Characteristics of Dyslexia, Dyslexia Assessment and Intervention

\section{Introduction}

Dyslexia is a neurobiological, developmental, language-based learning disability that affects individuals' ability to learn to read (accuracy and fluency) and the development of spelling skills. Individuals with dyslexia have difficulty connecting spoken language and the printed word because they have deficits in the phonological component of language. Difficulty decoding words accurately and fluently can affect reading comprehension and vocabulary development $[1,2]$. Spelling difficulties may affect the production of written composition. Dyslexia can lead to poor academic performance, low self-esteem, and lack of motivation. It is not a sign of low intelligence, laziness, or poor vision, and occurs across the range of intellectual abilities $[3,4]$.

\section{Background}

Initially termed "word blindness" [5], the word dyslexia is of Greek origin, meaning having impaired (days) word (lexi from lexicon) and the suffix (ia). Developmental dyslexia is a condition present in individuals who have word-level difficulties in reading decoding and spelling; the most persistent problem seems to be spelling $[6,7]$.

According to the Individuals with Disabilities Education Act (IDEA), the working definition of dyslexia labels it as a "specific learning disability." It is "a disorder in one or more of the basic psychological processes involved in understanding or in using language, spoken or written, that may manifest itself in the imperfect ability to listen, think, speak, read, write, spell, or to do mathematical calculations, including conditions such as perceptual disabilities, brain 
injury, minimal brain dysfunction, dyslexia, and developmental aphasia." See 20 U.S.C. $\$ 1401$ (30) and 34 CFR $\$ 300.8$ (c) (10) (emphasis added) (IDEA, 2004). Dyslexia is distinguished from other learning disabilities due to its phonological core deficit and persisting spelling difficulties.

As a specific learning disability that is neurobiological in origin, dyslexia is characterized by difficulties with accurate and fluent word recognition and by poor spelling and decoding abilities. These difficulties typically result from a deficit in the phonological component of language that is often unexpected in relation to other cognitive abilities and the provision of effective classroom instruction [8, 9]. Simply stated, when a student with dyslexia begins to learn to read, $\mathrm{s} /$ he has difficulty at the phoneme or sound level which adversely impacts spelling and reading. Secondary consequences may include problems in reading comprehension and reduced reading experience that can impede growth of vocabulary and background knowledge [10].

\subsection{Risk Factors: Genetic and Neurological Components of Dyslexia}

Dyslexia is the outcome of multiple risk factors. Research has shown that dyslexia has a complex genetic basis. The prevalence of dyslexia is higher in those children who have a family history of dyslexia $[10,11]$. The risk of having dyslexia in first-degree relatives who have this reading and spelling disorder exceeds that in the general population [12]. (Pennington \& Olson, 2008). Studies have shown that young children with a family history of dyslexia have reduced activation in neural correlates of phonological processing before reading onset compared to those without family history of dyslexia [13]. However, dyslexia should not be considered as a pure genetic component, but as a multifactorial developmental disorder $[14,15]$.

Studies using magnetic resonance imaging (MRI) and other medical assessment devices provide evidence that most individuals with dyslexia have reduced brain volume, less-than-normal gray matter volume, and a significant reduction of the outer white matter compartment of the brain which contributes to a less efficient brain circuit for reading [16-18]. Several studies have indicated that in individuals with dyslexia, there is a shift in hemisphere dominance for reading from the left to the right hemisphere. Researchers have described this shift as a deficit in intrahemispheric "short" or malfunction in corticocortical connectivity $[19,20]$.

In dyslexia, there seems to be an atypical reliance on the right region of the brain instead of the left regions that are activated in typically developing readers during phonological awareness tasks [21]. This inefficient reading circuit is revealed in the difficulty individuals with dyslexia have in phonological process and awareness (i.e., the ability to identify and manipulate sounds) despite normal to above-normal cognitive abilities [2, 10, 22, 23]. Evidence from the literature indicates that the small activation in the left regions for phonological processing in dyslexia is linked to phonological awareness deficits as the cause for dyslexia.

In addition to challenges with phonological awareness, researchers have asserted that rapid automatized naming (RAN) deficits contribute to reading difficulties and are apparent in some individuals with developmental dyslexia [24, $25,26]$. By definition, RAN is the rate with which a person can name a series of visually-familiar stimuli like letters, colors, and numbers [27], and indicates automaticity of processes that are essential to reading [28].

Impairments in the working memory phonological loop (RAN) and switching/flexible attention (rapid automatic switching [RAS]) have been suggested as hallmarks of dyslexia [28]. Although RAN and phonological processes affect reading, they contribute differently to the acquisition of reading skills and are activated in different hemispheres and brain regions. Authorities in the field have suggested that individuals with deficits in both phonological processing and RAN, the "double-deficit," have more severe difficulties in reading than those with single deficits [28-30].

\subsection{Characteristics of Individuals with Dyslexia}

As with most learning deficits, dyslexia presents with a wide array of characteristics in the individuals it affects. Further, throughout the development from childhood to adulthood, the difficulties encountered by individuals with dyslexia are manifested differently. Young children have difficulty associating sounds with letters, while older individuals have problems with reading fluency, spelling, and written expression. These challenges persist into adulthood [2, 6 ,]. Identifying the signs of dyslexia requires knowing the features of the condition depending on the age at which it is first determined to exist.

As aforementioned, researchers have identified preschool children with dyslexia based on a familial predisposition to the condition [2, 10] Thompson et al., 2015). Most common dyslexia characteristics of this preschool, pre-literate population include challenges in learning to speak, learning sound and letters, colors and numbers, handwriting, fine motor skills and sight word identification. The difficulties these children have with phonology often suggest they may develop a reading impairment as they mature [10,31].

Older children with dyslexia may have poor handwriting, difficulty learning foreign languages, problems organizing language, memorizing difficulties, spelling errors and persistent reading, writing and calculating difficulties [10]. In written language, spelling and recall of multi-syllable words may be noted. In reading skills, comprehension and decoding may be a challenge, and slow and often inaccurate reading skills may be noted. Individuals with dyslexia often show deficits in phonological word coding, such as understanding the sounds and meanings or words [2].

The importance of phonological abilities on reading and writing has been validated across languages but is even more challenging in language such as English where orthographic symbols are not as transparent or correlation as their corresponding sound [32]. Due to this, English-speaking individuals with dyslexia often require reading and spelling instruction [6]. 
Cognitively, it has been shown that individuals with dyslexia have difficulty with recognition of hidden shapes, [33] poor ability to shift their focus of attention, and deficits in aspects of working memory related to spoken and written language (the phonological loop) [34]. In fact, one of the most frequently named characteristics of dyslexia involves working memory. When working memory is impaired, a person with dyslexia has difficulty with the temporary storage of information while engaged in other cognitive activities at the same time [35]. The role of verbal working memory becomes more connected with vocabulary knowledge influencing adolescents' ability to read fluently [36].

Another aspect of working memory includes the orthographic loop (which provides for the ability to form letters, spell, read and write) and the morphological loop (which allows for vocabulary and reading development). Individuals with dyslexia have been shown to have challenges with the orthographic loop and the morphological loops of working memory, and thus present with errors of the aforementioned skills [34]. Instruction for middle childhood and adolescents with dyslexia must address the interrelationships among phonology, morphology, and orthography because English and most other languages have a morphophonemic orthography [34, 37].

Another population of individuals-those who are gifted but also have dyslexia-present interventionists, diagnosticians and language specialists with unique challenges. These individuals, termed "twice exceptional" often outperform normal peers on verbal, working memory and language skill tasks but have delays in phonological awareness and rapid naming tasks. They also demonstrate very high verbal reasoning, and further, the challenge for teachers and parents of these individuals thus lies in identification of dyslexia as abilities of gifted individuals with dyslexia often mask the effects of dyslexia on oral and written language tasks as well as standardized tests [38], while core deficits associated with dyslexia remain [39].

Similarly, characteristics of adults with dyslexia are often less obvious as often the individual has learned how to compensate for the condition and its associated challenges. However, cognitive challenges such as poor phonological awareness and rapid naming skills, deficits in working memory and written language may remain [40-42], along with other cognitive and literacy issues [43].

\subsection{A Word on Reversals and Corresponding Conditions}

Not all individuals with dyslexia make reversals. Although individuals with dyslexia have a higher incidence of reversals than those without dyslexia, not all individuals with dyslexia demonstrate this characteristic [10, 44].

Some individuals with dyslexia may present with other conditions also affected by working memory deficits, such as writing difficulties. As dysgraphia has been shown to occur concurrently with dyslexia, researchers point to cognitive assessments of attention regulation and working memory for individuals with these co-occurring disabilities to best plan treatment $[10,45]$.

Table 1. Summary of Characteristics of Individuals with Dyslexia.

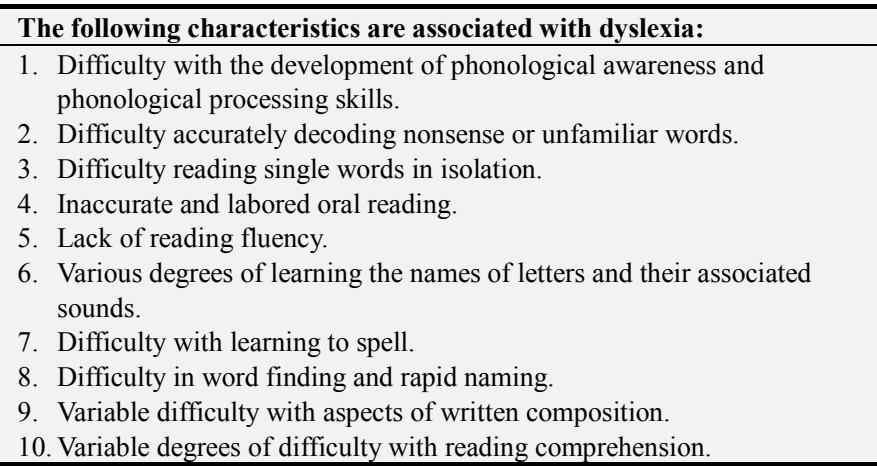

\section{Identification and Assessment}

Identification of individuals with dyslexia can be challenging, as IQ test and language are not necessarily indicative of the disorder. The most tried-and-true indicator that a student may have dyslexia is difficulty learning how to read. Early identification of children at risk for reading difficulties may help assess and address this condition as soon and as optimally as possible. Because dyslexia is a specific learning disability in word reading and spelling (written language) characterized by impairments in verbal working memory, assessment measures of word reading (i.e., real words and pseudo words), spelling, and working memory are necessary for the identification of individuals with dyslexia. The assessments listed below (Table 2) are suggested measures for reading and writing outcome and working memory.

Table 2. Tests for Dyslexia.

\footnotetext{
Some of the most commonly used tests for dyslexia include:

1. Comprehensive Test of Phonological Processing (CTOPP)-measure of phonological coding

2. Delis Kaplan Executive Function System (D-KEFS)-Color Word Form Inhibition and Verbal Fluency Letters subtests.

3. Gray Oral Reading Test, Fifth Edition (GORT-5)-Accuracy and rate of oral reading of connected text.

4. Process Assessment of the Learner, Second Edition: Diagnostics for Reading and Writing (PAL-II Reading and Writing).

5. RAN/RAS: Rapid Automatized Naming and Rapid Alternating Stimulus Tests.

6. Test of Word Reading Efficiency, Second Edition (TOWRE-2)-Phonemic Decoding Efficiency and Sight Word subtests.

7. Wechsler Individual Achievement Test, Third Edition (WIAT-III) -Spelling subtest.

8. Wechsler Fundamentals: Academic Skills.

9. Wide Range Achievement Test 4 (WRAT4)-Spelling subtest.

10. Woodcock Reading Mastery Tests, Third Edition (WRMT -III)-The Word Identification and the Word Attack subtest.
} 


\section{Intervention Strategies}

Once identified, individuals with dyslexia will benefit from programs targeting letters and phonemes as well as tasks addressing reading strategies. Word training and decoding skills, and the use of computers to aid in writing have also proven beneficial to this population, in individuals as young as kindergarten age $[10,46]$.

\section{Conclusion}

It is suggested that as many as 10 percent of the population is affected by dyslexia. With the compounding reading and spelling difficulties that are common to persons with dyslexia, education and vocation can be adversely affected in this population if dyslexia is not identified and managed as early and as effectively as possible.

Common risk factors for dyslexia include having a genetic predisposition and/or a family member with dyslexia. Imaging studies suggest right-hemisphere reliance in the brain during typically left-hemisphere dominant phonological tasks can be observed in persons with dyslexia. Impairments in phonological processing and awareness while normal or above-normal cognitive abilities may also exist in persons with dyslexia and can cause difficulty and frustration.

Early identification of dyslexia relies on early symptom recognition. Common characteristics include difficulty associating sounds with letters, reading dysfluencies, spelling difficulties, challenges with written expression and poor handwriting. Tests for dyslexia guide professions in identification and treatment of the condition. Once identified, strategies to enhance word training and improve decoding skills have shown to benefit the reading and writing abilities of persons with dyslexia.

In this paper, we have attempted to highlight information regarding the characteristics persons with dyslexia often present with, as well as review assessment, identification and intervention strategies currently available. Studies have suggested that this unique population often presents with normal to above-normal intelligence, and just as often, normal language skills.

Thus the need for educators, physicians and professionals to be armed with specific key factors regarding dyslexia and its identification cannot be understated. Overall, this work wants to provide information and encourage early assessment and intervention for children at high-risk for presenting with dyslexia.

\section{References}

[1] Kim, Y. S., Wagner, R. K., \& Lopez. D. (2012). Developmental relations between reading fluency and reading comprehension: A longitudinal study from Grade 1 to Grade 2. Journal of Experimental Child Psychology, 113, 93-111.

[2] Snowling, M. J. (2019). Dyslexia: A very short introduction. Oxford, UK: Oxford University Press.

[3] Berninger, V. W., Lee, YL., Abbott, R. D., \& Breznitz, Z.
(2013). Teaching children with dyslexia to spell in a reading-writers' workshop. Annals of Dyslexia 63: 1, 1-24. https://doi.org/10.1007/s11881-011-0054-0

[4] Denton, C. A., Fletcher, J. M., Anthony, J. L., \& Francis, D. J. (2006). An evaluation of intensive intervention for students with persistent reading difficulties. Journal of Learning Disabilities, $\quad 39 \quad$ (5), $447-466$. https://doi.org/10.1177/00222194060390050601

[5] Campbell, T. (2011). From aphasia to dyslexia, a fragment of a genealogy: An analysis of the formation of a 'medical diagnosis,' Health Sociology Review, 20: 4, 450-461, doi: 10.5172/hesr.2011. 20.4.450.

[6] Berninger, V. W., Raskind, W., Richards, T., Abbott, R., \& Stock, P. (2008). A multidisciplinary approach to understanding developmental dyslexia within working-memory architecture: Genotypes, phenotypes, brain, and instruction. Developmental Neuropsychology, 33: 6, 707-744, doi: 10.1080/87565640802418662.

[7] CNRS. (2017, November 28). Dyslexia: When spelling problems impair writing acquisition. ScienceDaily. Retrieved $\begin{array}{llll}\text { August } & 12, & 2019 & \text { from }\end{array}$ www.sciencedaily.com/releases/2017/11/171128112649.htm

[8] Callens, M. \& Brysbaert, M. (2020). Cognitive profile of students with dyslexia entering post-secondary education. In D. Perlin, (Ed.), The Wiley Handbook of Adult Literacy, 1st ed. New Jersey: Wiley \& Sons.

[9] Lyon, G. R., Shaywitz, S. E., \& Shaywitz, B. A. (2003). Defining dyslexia, comorbidity, teachers' knowledge of language and reading: A definition of dyslexia. Annals of Dyslexia, 53, 1-14. http://dx.doi.org/10.1007/s11881-003-0001-9

[10] International Dyslexia Association (IDA, 2019). Dyslexia Basics. Retrieved from https://dyslexiaida.org/dyslexia-basics-2/

[11] Thompson, P. A., Hulme, C., Nash, H. M., Gooch, D., Hayiou-Thomas, E., \& Snowling, M. J. (2015). Developmental dyslexia: Predicting individual risk. Journal Of Child Psychology \& Psychiatry, 56 (9), 976-987. doi: 10.1111/jcpp.12412.

[12] Pennington, B. F., \& Olson, R. K. (2005). Genetics of dyslexia. In M. J. Snowling \& C. Hulme (Eds.), Blackwell Handbooks of Developmental Psychology.

[13] Raschle, N., Zuk, J., \& Gaab, N. (2012). Functional characteristics of developmental dyslexia in left-hemispheric posterior brain regions predate reading onset. Proceedings of the National Academy of Sciences of the United States of America. 109. 2156-61. 10.1073/pnas. 1107721109 .

[14] Mascheretti, S., De Luca, A., Trezzi, V., Peruzzo, D., Nordio, A., Marino, C., \& Arrigoni, F. (2017). Neurogenetics of developmental dyslexia: From genes to behavior through brain neuroimaging and cognitive and sensorial mechanisms. Translational Psychiatry, 7 (1), e987.

[15] Van Bergen, E., De Jong, P. F., Maassen, B., \& van der Leij, A. (2014). The effect of parents' literacy skills and children's preliteracy skills on the risk of dyslexia. Journal of Abnormal Child Psychology, 42 (7), 1187-1200. 
[16] Casanova, M. F., El-Baz, A. S., Giedd, J., Rumsey, J. M., \& Switala, A. E. (2010). Increased white matter gyral depth in dyslexia: Implications for corticocortical connectivity. Journal of Autism and Developmental Disorders, 40 (1), 21-29.

[17] Richards, T. L., Grabowski, T. J., Boord, P., Yagle, K., Askren, M., Mestre, Z., Robinson, P., Welker, O., Gulliford, D., Nagy, W. and Berninger, V., (2015). Contrasting brain patterns of writing-related DTI parameters, fMRI connectivity, and DTIfMRI connectivity correlations in children with and without dysgraphia or dyslexia. NeuroImage: Clinical, 8, pp. 408-421.

[18] Xu, M., Yang, J., Siok, W. T., \& Tan, L. H. (2015). Atypical lateralization of phonological working memory in developmental dyslexia. Journal of Neurolinguistics, 33, 67-77.

[19] Pugh, K. R., Mencl, W. E., Jenner, A. R., Katz, L., Frost, S. J., Lee, J. R., Shaywitz, S. E. and Shaywitz, B. A., 2001. Neurobiological studies of reading and reading disability. Journal of Communication Disorders, 34 (6), 479-492.

[20] Shaywitz, S. E. (2003). Overcoming dyslexia: A new and complete science-based program for reading problems at any level. Knopf.

[21] Kovelman, I., Norton, E. S., Christodoulou, J. A., Gaab, N., Lieberman, D. A., Triantafyllou, C., Wolf, M., Whitfield-Gabrieli, S. and Gabrieli, J. D., 2011. Brain basis of phonological awareness for spoken language in children and its disruption in dyslexia. Cerebral Cortex, 22 (4), pp. 754-764.

[22] Jensen, J., \& Brieger, D. (2005). Learning disorders. In K. Cheng \& K. Myers (Eds.), Child and Adolescent Psychiatry: The essentials (pp. 281-298). Philadelphia: Lippincott, Williams and Wilkins.

[23] King, B., Wood, C., \& Faulkner, D. (2008). Sensitivity to visual and auditory stimuli in children with developmental dyslexia. Dyslexia, 14 (2), 116-141.

[24] Ackerman, P. T., \& Dykman, R. A. (1993). Phonological processes, confrontational naming, and immediate memory in dyslexia. Journal of Learning Disabilities, 26 (9), 597-609.

[25] Katzir, T., Kim, Y. S., Wolf, M., Morris, R., \& Lovett, M. W. (2008). The varieties of pathways to dysfluent reading: Comparing subtypes of children with dyslexia at letter, word, and connected text levels of reading. Journal of Learning Disabilities, 41 (1), 47-66.

[26] Wolf, M., \& Bowers, P. G. (1999). The double-deficit hypothesis for the developmental dyslexias. Journal of Educational Psychology, 91 (3), 415.

[27] Denckla, M. B., \& Rudel, R. G. (1976). Rapid 'automatized'naming (RAN): Dyslexia differentiated from other learning disabilities. Neuropsychologia, 14 (4), 471-479.

[28] Norton, E. S., \& Wolf, M. (2012). Rapid automatized naming (RAN) and reading fluency: Implications for understanding and treatment of reading disabilities. Annual Review of Psychology, 63, 427-452.

[29] Compton, D. L., Defries, J. C., \& Olson, R. K. (2001). Are RAN - and phonological awareness-deficits additive in children with reading disabilities? Dyslexia, 7 (3), 125-149.

[30] King, W. M., Giess, S. A., \& Lombardino, L. J. (2007). Subtyping of children with developmental dyslexia via bootstrap aggregated clustering and the gap statistic: comparison with the double - deficit hypothesis. International Journal of Language \& Communication Disorders, 42 (1), 77-95.

[31] Nash, H. M., Hulme, C., Gooch, D., \& Snowling, M. J. (2013) Preschool language profiles of children at family risk of dyslexia: continuities with specific language impairment. Journal of Child Psychology \& Psychiatry, 54 (9), 958-968. doi: $10.1111 /$ jcpp.12091.

[32] Ziegler, J. C., \& Goswami, U. (2005). Reading acquisition, developmental dyslexia, and skilled reading across languages: a psycholinguistic grain size theory. Psychological Bulletin, $131(1), 3$

[33] Martinelli, V. v., \& Schembri, J. (2014). Dyslexia, spatial awareness and creativity in adolescent boys. Psychology of Education Review, 38 (2), 39-47.

[34] Berninger, V. W., Richards, T. L., \& Abbott, R. D. (2015). Differential diagnosis of dysgraphia, dyslexia, and OWL LD: Behavioral and neuroimaging evidence. Reading and Writing, 28 (8), 1119-1153.

[35] Baddeley, A. (1992). Working memory: The interface between memory and cognition. Journal of Cognitive Neuroscience, 4 (3), 281-288.

[36] Shaywitz, S. E., Morris, R., \& Shaywitz, B. A. (2008). The education of dyslexic children from childhood to young adulthood. Annual Review of Psychology, 59, 451-475.

[37] Cahill, L., Tiberius, C., \& Herring, J. (2013). PolyOrth: Orthography, phonology and morphology in inheritance lexicons. Written Language \& Literacy, 16 (2), 146-185.

[38] van Viersen, S., Kroesbergen, E. H., Slot, E. M., \& de Bree, E. H. (2016). High reading skills mask dyslexia in gifted children. Journal of Learning Disabilities, 49 (2), 189-199.

[39] Nielsen, K., Abbott, R., Griffin, W., Lott, J., Raskind, W., \& Berninger, V. W. (2016). Evidence-based reading and writing assessment for dyslexia in adolescents and young adults. Learning disabilities (Pittsburgh, Pa.), 21 (1), 38.

[40] Berch, D. B. (2011). Working memory limitations in mathematics learning: Their development, assessment, and remediation. Perspectives on Language and Literacy, 37 (2), 21.

[41] Bogdanowicz, K. M., Łockiewicz, M., Bogdanowicz, M., \& Pąchalska, M. (2014). Characteristics of cognitive deficits and writing skills of Polish adults with developmental dyslexia. International Journal of Psychophysiology, 93 (1), 78-83.

[42] Kilpatrick, D. A. (2015). Essentials of assessing, preventing, and overcoming reading difficulties. John Wiley \& Sons.

[43] Chung, K. K., Ho, C. S. H., Chan, D. W., Tsang, S. M., \& Lee, S. H. (2011). Cognitive skills and literacy performance of Chinese adolescents with and without dyslexia. Reading and Writing, 24 (7), 835-859.

[44] Brooks, A. D., Berninger, V. W., \& Abbott, R. D. (2011). Letter Naming and Letter Writing Reversals in Children With Dyslexia: Momentary Inefficiency in the Phonological and Orthographic Loops of Working Memory. Developmental Neuropsychology, 36 (7), 847-868. 
[45] Lopes-Silva, J. B., Moura, R., Júlio-Costa, A., Wood, G., Salles, J. F., \& Haase, V. G. (2016). What is specific and what is shared between numbers and words? Frontiers in Psychology, 7 , 22.
[46] Drigas, A. D., \& Elektra, B. E. (2016). Dyslexia and ICTs, Assessment and Early Intervention in Kindergarten. International Journal of Emerging Technologies in Learning, 11 (2), 53-56. doi: 10.3991/ijet.v11i2.5193. 